\title{
Frontières
}

\section{Théâtre funeste}

\section{Pascal Huot}

Volume 21, numéro 1, automne 2008

Prévenir le suicide

URI : https://id.erudit.org/iderudit/037884ar

DOI : https://doi.org/10.7202/037884ar

Aller au sommaire du numéro

Éditeur(s)

Université du Québec à Montréal

ISSN

1180-3479 (imprimé)

1916-0976 (numérique)

Découvrir la revue

Citer ce document

Huot, P. (2008). Théâtre funeste. Frontières, 21(1), 133-133.

https://doi.org/10.7202/037884ar

Ce document est protégé par la loi sur le droit d'auteur. L'utilisation des services d'Érudit (y compris la reproduction) est assujettie à sa politique d'utilisation que vous pouvez consulter en ligne.

https://apropos.erudit.org/fr/usagers/politique-dutilisation/
Cet article est diffusé et préservé par Érudit.

Érudit est un consortium interuniversitaire sans but lucratif composé de l’Université de Montréal, l'Université Laval et l'Université du Québec à Montréal. Il a pour mission la promotion et la valorisation de la recherche. https://www.erudit.org/fr/ 


\section{THÉÂTRE FUNESTE}

\section{Pascal Huot, \\ M.A. en ethnologie, artiste multidisciplinaire.}

La création artistique est depuis toujours une exploration orientée à la fois vers la recherche de nouveaux symboles d'expression et vers les fondements mêmes d'une révolution. Dans cette optique, l'art induit dans la conscience humaine une réflexion sur le monde et ses objets. Au confluent des pensées, la fonction heuristique de l'art en appelle au doute, au nébuleux, à l'incertain. Issu d'une expérience personnelle au cœur d'une collectivité contrastée, Théâtre funeste consiste en une démonstration de la gestualité du réel soumise au vocabulaire de la matière plastique. La réalité, dans son côté obscur, est exposée aux yeux du spectateur qui est ainsi contraint à la double réflexion de l'esthétique et du sujet.

Les créations qui composent Théâtre funeste sont à la fois survivance d'une manière de sentir, de vivre et d'exprimer ce qui nous lie au réel, mais elles suscitent aussi une vision toujours renouvelée, apte à faire naître des réalités ignorées, subverties par l'être humain. L'œil se doit ainsi d'exécuter la distance, de pénétrer à travers le passage nécessaire, d'effectuer une transition de l'œuvre vers la signification symbolique du message. L'œuvre n'a pas un seul sens à offrir, elle ouvre plutôt ses horizons à une errance de significations que son observateur, par l'immersion de sa propre personnalité, fera émerger. Ainsi, l'art véhiculé par ces œuvres exécute le lien terrestre entre la matière et la vie.

Car Théâtre funeste parle de la fin dans ce qu'elle véhicule de paradoxal, exprimant à la fois ce point d'arrêt ultime, mais aussi le terme, le but, la finalité de toute matière. Chaque œuvre, constituée de manière indépendante, se retrouve sous une bannière, celle de la mort, et par conséquent, du début, de la suite qui doit avoir lieu à

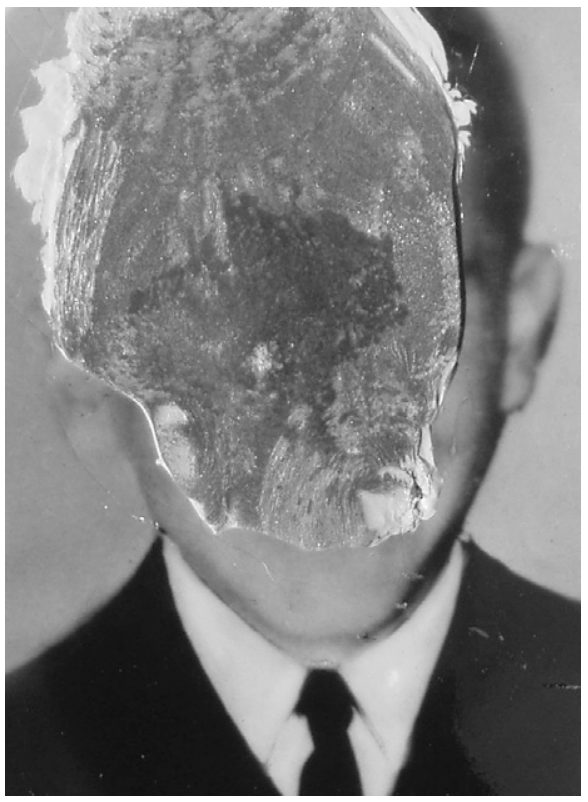
l'état de possible. Par leur mise en scène extérieure, par l'empreinte du visible, le sang, le rouge qui coule, exprimant à la fois violence, silence, expiation de la vie, l'œuvre amorce un second souffle. Les matériaux, toujours torturés par une âme meurtrie, laissent entrevoir une seconde vie par la redite de la matière sous une forme nouvelle.

Théâtre funeste est violence. Théâtre funeste est limite. Théâtre funeste est confrontation. Mais en bout de piste, Théâtre funeste est naissance, changement, bouleversement. Il s'oppose à l'apathie générale face à la violence quotidienne. Violence galvaudée par les médias qui font défiler la douleur, le massacre devant des regards certes touchés, mais déshumanisés. Voilà le regard confronté, l'humain remis en cause, le spectateur face à lui-même. Se dévoilent alors toute la détresse et la beauté du drame, la répulsion, le dégoût, mais aussi la fascination, une Mort de Sardanapale contemporaine. L'œuvre transcende ainsi l'acte par la poétisation de la fin, par cet apex où déferle l'esthétisme de la mort. Tous médiums exploités, invoqués, dessin, peinture, sculpture, photographie, ramènent à un univers émotif, à une façon d'exister dans le monde, au cœur d'une réalité qui déborde de son sujet, où l'enrichissement du visuellement beau tend vers une ultime réflexion en ce théâtre de barbarie.

\section{DÉMARCHE ARTISTIQUE}

Dans mes présentes recherches artistiques, je pose le problème de la dichotomie de l'esthétisme et du mortuaire par le biais de la création d'un nouvel espace plastique où le visuellement beau côtoie l'acte de la fin. Mon questionnement naît de la fréquentation incessante de l'humain avec une fin, la mort, qu'il exclut de sa vision. Mon art opte ainsi pour une esthétisation d'un acte tantôt naturel, tantôt malsain où sont invoqués et explorés l'exposition physique de la gestuelle de création et l'éclatement de la censure dans la dynamique du sang commémoré. L'œuvre se développe ainsi visuellement par l'apposition et la confrontation du beau et du repoussoir.

Plus encore, ce qui fait sens pour moi, c'est la confrontation avec mes œuvres. Tous les événements de ma vie ont une incidence sur ma production et sur le développement de mon art. Je propose une photogénie plastique précise où l'objet étudié implique qu'il doit être observé dans sa matérialité, dans sa structure, dans sa dynamique, ainsi que dans son histoire réelle au sein de l'acte avenu. Travail de continuité, où la réflexion précède chaque œuvre et en appelle une autre, les frontières entre art et réflexion émergent lorsque l'œil fixe l'œuvre terminée. Les œuvres témoignent d'un passé et constituent un prolongement de la réflexion amorcée. Je cherche à prendre une distance avec l'objet conventionnel pour centrer ma démarche vers l'essence même du réel. Je veux apprivoiser la réalité qui m'entoure par le biais de l'art plastique, médium qui permet de s'exprimer sous divers modes d'expression, par la description du réel dans sa substance.

Je veux pousser les possibilités plastiques à l'extrême, au radical, où la liquidation de l'inertie plastique se développe dans une poétisation de la fin. En explorant divers médiums, l'œuvre n'est pas enfermée dans un carcan strict, elle évolue au contraire dans le vaste du possible où l'acte à poser devient une réflexion sur notre société où les choix personnels comme collectifs révèlent ainsi la cause de l'action. 